\title{
EL ARENAL DE SEVILLA O EL DISCURSO HISPALENSE DE LOPE DE VEGA EN 1603
}

Es hasta cierto punto comprensible que las dimensiones sobrehumanas de la obra dramática de Lope hayan inducido una medida de inercia estudiosa que hoy benignamente se diagnostica como cierto "quietismo" crítico ${ }^{1}$. La dificultad de un conocimiento totalizador, reducido por lo común a unas cuantas obras dadas por supremas pero apenas jerarquizadas, las generalizaciones superficiales, los textos mal o insuficientemente editados $^{2}$ sin duda infunden a priori el desaliento. Una categoría que como la comedia de capa y espada, lleva la parte del león en su "comediaje"3 se ha visto menospreciada, de don José Mor de Fuentes ${ }^{4}$ acá, como un molde de tipos y situaciones en mecánica explotación conducente al hastío. Sólo en el ocaso del $\mathrm{xx}$, cabe decir le llega por fin la hora de ser vista como un concepto de singular éxito ${ }^{5}$, capacitador eficaz de la relación

${ }^{1}$ Joan Oleza, "Los géneros en el teatro de Lope de Vega: el rumor de las diferencias", Del horror a la risa: Los géneros dramaticos clásicos. Homenaje a Christiane Faliu-Lacourt, eds. I. Arellano et al., Reichenberger, Kassel, 1994, p. 236.

${ }^{2}$ Ignacio Arellano, "La edición de textos teatrales del Siglo de Oro. Notas sueltas sobre el estado de la cuestión", La comedia, ed. J. Canavaggio, Casa de Velázquez, Madrid, 1990, pp. 13-50; JoAn Oleza, "El nacimiento de la comedia: estado de la cuestión", La comedia, ed. J. Cannavagio, Casa de Velázquez, Madrid, 1995, pp. 181-226.

${ }^{3}$ Luis de Góngora y Argote, "A Lope de Vega", Obras completas, eds. J. e I. Millé y Giménez, Aguilar, Madrid, 1966, p. 538.

4 Ildefonso Manuel Gil, "El teatro de Mor de Fuentes", Miscelánea ofrecida a José M. Lacarra y de Miguel, Zaragoza, 1968, pp. 279-289 (por lo demás, salada recapitulación decimonónica de Ignacio de Luzán en su Poética sobre la comedia y sus trucos).

${ }^{5}$ Renovadoras perspectivas de Marc Vitse, en especial "La classifications des genres", en Elements pour une théorie du théatre espagnol du XVII ${ }^{e}$ siécle, Presses Universitaires du Mirail-France-Iberie Recherche, Toulouse, 1990, pp. 306-333. 
autor-público, adaptable a casi cualquier tipo de discursos escénicos y de un modo u otro acogedora de complejas y multiformes tensiones de época. Un terreno, por tanto, agradecido y siempre de alto rendimiento en su laboreo interdisciplinar. Como dijo hace un siglo Ezra Pound, la calidad del teatro "tiene que llegar más allá de las candilejas"6.

Proceden tales consideraciones de su oportunidad en relación con la comedia de Lope El arenal de Sevilla ${ }^{7}$, pieza destacada del corpus de unas veintidós de ellas que el Fénix dedicara a la bella ciudad y ejemplo señero de la de capa y espada en su modalidad de comedia urbana ${ }^{8}$. La pieza, todavía escasamente estudiada, es un himno celebratorio, concentrado sobre aquellas playas del Guadalquivir, donde corre la savia económica de ambos mundos y son fachada singular de Sevilla cara a su tiem$\mathrm{po}^{9}$. Para Lope, un hombre moderno ya como nosotros, Sevilla

6 "La calidad de Lope de Vega", CuH, 59 (1954), p. 141. De su libro, The spirit of romance (1910).

7 Incluida en la primera lista de El peregrino en su patria (1604) e impresa en la Oncena parte de las comedias de Lope (Madrid, 1618). De ediciones modernas, la acoge Obras de Lope de Vega. Obras dramáticas, Real Academia Española, Madrid, 1937, t. 11, pp. 365-397 (textos aquí citados); Comedias, Biblioteca Castro Turner, Madrid, 1995, t. 12, pp. 423-512; El arenal de Sevilla, introd. y notas R.M. Serrera Contreras, Ayuntamiento de Sevilla, Sevilla, 2005.

8 Ignacio Arellano, "El modelo temprano de la comedia urbana de Lope de Vega", Lope de Vega: comedia urbana y comedia palatina. Actas de las XVIII jornadas de teatro clásico, eds. F.B. Pedraza y R. González Cañas, Universidad de Castilla-La Mancha-Festival de Almagro, Almagro, 1996, pp. 37-59; CÉsAr Oliva, "El espacio urbano en la comedia urbana y la comedia palatina de Lope de Vega", en ibid., pp. 13-36.

9 Ruth Pike, Aristocrats and traders. Sevillian society in the Sixteenth Century, Cornell University Press, Ithaca-London, 1972, pp. 203-204; Pierre et Huguette Chaunu, Seville et l'Atlantique, 8 ts., Armand Colin, Paris, 19551960, resumen "El puerto, el río", en Sevilla y América. Siglos XVI y XVII, Anales de la Universidad Hispalense, Sevilla, 1983; Francisco Morales Padrón, "El complejo puerto-río", Historia de Sevilla. La ciudad del quinientos, Universidad, Sevilla, 1986, pp. 29-34; Antonio Domínguez Ortiz, "La ciudad. El río”, Historia de Sevilla. La Sevilla del siglo XVII, Universidad, Sevilla, 1986, pp. 35-65; José M. Caballero Bonald, Sevilla en tiempos de Cervantes, Editorial Planeta, Barcelona, 1991, pp. 74-78; José L. Comellas, Sevilla, Cádiz y América: el trasiego y el tráfico, Editorial Arguval, Málaga, 1992; HéCTOR BRIOso SANTos, "Sevilla puerto y puerta de Indias. ¡Mal hayan Indias y mares!", Sevilla en la literatura del Siglo de Oro. El sentimiento anticiudadano barroco, Ayuntamiento de Sevilla, Sevilla, 1998. Generalidades en Santiago Montoto DE SEdas, El arenal de Sevilla en la historia y la literatura, Silverio Domínguez, Sevilla, 1934. Nostalgias de exiliado en Manuel Blasco Garzón, "El are- 
es única por ese corto espacio, libre de casas lo mismo que de orden, gobierno e inhibiciones de todo género. El Arenal hispalense no es un lugar de habitación, sino de tránsito, como suma de proyectos vitales que lo mismo surgen que se vienen al suelo. Nadie allí reposa, calla ni pernocta, porque su razón de ser postula el transcurso de una perenne aventura en cambiante y siempre renovada sorpresa. Lo mismo que también un ámbito no jerarquizado, en que cada uno va como puede a lo suyo, imperan sin freno pasiones e intereses y la llamada justicia no pasa de nominal. No existe autoridad que aspire (ni aun se atreva) a imponer en el Arenal ninguna ley y cada uno asume allí las consecuencias nudas e inmediatas de su conducta. Otro espacio similar a extramuros de la ciudad, pero a menor escala es su matadero, maravillosamente captado por Cervantes en el Coloquio de los perros ${ }^{10}$. El complejo epifenómeno de la vida bajo forma libre, que nadie ni nada regula, es nuevo y desconcertante para todos, incluyendo a los poetas, para los que Grecia, Roma y el Medievo no tienen en esto mucho que enseñarles.

El Arenal de Sevilla es una pieza típica del arsenal dramático de Lope ${ }^{11}$, con unidad de acción y de lugar (salvo una escena en la ciudad) aunque no de tiempo. Parte allí de una clara fórmula que es el teatro de inspiración en el mundo real que la Propalladia (1517) de Bartolomé de Torres Naharro definía como "a noticia" debido a su reflejo en crudo de la realidad ${ }^{12}$. Aspecto que hoy diríamos "documental", muy fuerte en toda la

nal de Sevilla”, Evocaciones andaluzas. Una interpretación apasionada, Librería Pulido, Buenos Aires, 1941, pp. 33-43.

${ }^{10}$ La gran diferencia es el contraste de su presentación negativa. Véase Juan de Mata Carriazo, "Negros, esclavos y extranjeros en el barrio sevillano de San Bernardo (1617-1629)", Archivo Hispalense, 20 (1954), 121-133.

11 Sobre el protagonismo de la ciudad y su puerto, Jean Canavaggio, “«El arenal de Sevilla», o el arte nuevo de ambientar una comedia”, Corónente tus hazañas. Studies in Honor of John Jay Allen, ed. J. McGrath, Juan de la Cuesta, Newark, DE, 2005, pp. 52-62. Acerca del Arenal como "estructura predominante", BARbara E. KurTz, “«El arenal de Sevilla»: circunstancialidad y simbolismo analógico de una comedia lopesca”, BC, 37 (1985), 191-114; MANUEL CoRnEJO, "Quelques réflexions sur la ville et sa representation dans «El arenal de Sevilla» de Lope de Vega", Similitud y verosimilitud en el teatro del Siglo de Oro, ed. I. Núñez, Universidad de Navarra, Pamplona, 2005, pp. 148-166.

12 John Lihani, Bartolomé de Torres Naharro, Twayne Publishers, Boston, 1979, p. 154. Siendo de recordar JosePH E. Gillet: "Torres Naharro's drama... is not only unclassical; it is anti-classical" ("Propalladia" and other works of Bartolomé de Torres Naharro, University of Pennsylvania, Philadelphia, 1961, t. 4, p. 568). Herencia para el teatro posterior, Stanislav Zimic, El 
obra y que es puesto de relieve por la especie de visita guiada al mundo del Arenal que cubre todo el primer acto. Ocurre en temporada de armamentos militares, con perspectiva de una imaginaria expedición a Argel y cuando, sobre todo, acaba de partir la flota anual de Indias, porque El Arenal de Sevilla es a la letra ombligo del mundo, en cuanto vía de comunicación con ultramar ${ }^{13}$. Van y vienen por el río naves de todo el orbe y por su puerto entra y sale toda suerte de mercancías, con la plata apilada en fardos igual que otro cargamento cualquiera:

\author{
Toda España, Italia y Francia \\ vive por este Arenal: \\ porque es plaza general \\ de todo trato y ganancia (I, 370).
}

La obra es, en lo externo, un vistazo impresionista que Lope maneja con un claro sentido escénico y en particular pre- o paracinematográfico, incluyendo en su visión el compromiso de incluir naves y ambiente marinero en el espacio reducidísimo de aquellos escenarios de entonces. Y lo cual hace por resolver a su manera, siendo muy de notar acotaciones escénicas tan cuidadas como "Véanse unas proas de barcos con ramos, y dos o tres Arráez con remos"14.

La complacencia de Lope gira, sin embargo, en torno a un abigarrado y non sanctum desfile humano. Viene allí citada

pensamiento humanístico y satírico de Torres Naharro, 2 ts., Sociedad Menéndez Pelayo, Santander, 1977-1978.

13 A. García-BaQuero González, Andalucía y la carrera de Indias, 14921824, Sevilla, 1986. Otra animada pintura del río en días de flota en Francisco LuQue Faxardo, Fiel desengaño de la ociosidad y los juegos, Real Academia Española, Madrid, 1955, t. 1, pp. 60-61.

${ }^{14}$ I, p. 367. Lope comienza a interesarse en las tramoyas y "apariencias" que hoy se llamarían decorados y que más adelante, habrían de causarle algunos dolores de cabeza a manos de ciertos colegas; véase EUGENIO AsENSIO, "Tramoya contra poesía. Lope atacado y triunfante", Teoría y realidad en el teatro español del siglo XVII. La influencia italiana, Instituto Español de Cultura, Roma, 1981, pp. 257-270. Papel hispalense en los primeros pasos de dicha innovación, en Jean Sentaurens, "La edad de oro de la comedia en Sevilla: los malogrados comienzos de una modernidad temprana”, La Comedia, 1995, 145-153. Corroborado por Mercedes de los Reyes PeÑa, "El espacio urbano de Sevilla en obras dramáticas del Siglo de Oro: una loa y un auto sacramental sobre «Las grandezas de Sevilla»", Homenaje a Frédéric Serralta. El espacio y sus representaciones en el teatro español del Siglo de Oro, eds. F. Cazal et al., Iberoamericana-Vervuert, Madrid-Frankfurt/M., 2002, pp. 451-495. 
para una merienda cierta mulata con otros criados, sudorosa por venir caminando desde la calle de la Feria hasta la Puerta Real, pero no ha acudido su galán y, malhumorada, termina por conformarse con un sustituto allí nada arduo de encontrar. Ciertos galeotes turcos, custodiados por soldados, levantan en tierra una tienda y aprovechan la ocasión y el poco (delicioso) castellano que saben para dar un "gatazo" (I, 369), que hoy diríamos timo, a cierto confianzudo paseante recién llegado de Castilla. El cuerpo de guardia de las galeras desatiende mientras tanto las armas en favor de montarse una timba en toda regla. Un aguador vende, cántaro y cestilla a cuestas, agua con anís ${ }^{15}$, y surge la trifulca de siempre entre corchetes concejiles y algunos soldados embarcados. Irrumpe también un ladrón perseguido por otro alguacil, pero lo burla arrojándose al agua. El Arenal es un cambiante espectáculo con el telón siempre levantado, al que se va para escuchar, ver y ser vistos. Así ocurre con los ociosos capitanes Fajardo y Castellanos, "del mar soldados" (I, 372) o infantería de marina que diríamos ahora, quienes se califican a sí mismos de anfibias "nutrias" y, a lo sempiterno, hablan nada más de política de mandos pero, sobre todo, de mujeres y aventuras fáciles. Lope ha desplegado hasta aquí una técnica de viñetas escénicas en visión panorámica de aquel extrarradio de Sevilla, con sus grupos de gente que se ocupa, trampea o divierte a orillas de su río. La única sorpresa es la ausencia de alguna representación eclesiástica, algo de veras extraño cuando la misma catedral se halla contigua al bullicioso Arenal, lo mismo que ocurre también con la bien poblada mancebía de la ciudad. Lope, es evidente, no desea el menor roce de problemas por ninguno de ambos lados.

Retratada como una Babilonia y una plaza universal donde "toda esta arena es dineros" (I, 365), el puerto-puerta ${ }^{16}$ de Sevilla vive como antesala de América y asimismo escenario de amor

15 Sobre vendedores populares, incluidos los de aguardiente, en el teatro de Lope, Miguel Herrero García, Oficios populares y sociedad de Lope, Castalia, Madrid, 1997, pp. 136-161. El cronista sevillano FrANCISCO DE ARIÑo informa con puntualidad acerca del Arenal y escándalos producidos por la abundancia de tablas de juego así como peleas entre corchetes y soldados (Sucesos de Sevilla de 1592 a 1604, Sociedad de Bibliófilos Andaluces, Sevilla, 1873).

16 Antón García-Baquero González y Ramón M. Serrera, Sevilla, puerto y puerta de las Indias, Universidad, Sevilla, 2005. Sobre la paranomasia puerto-puerta, M. CoRneJo, "Algunas funciones del espacio sevillano en las comedias de Lope de Vega", Memoria de la palabra. Actas del VI Congreso de AISO, ed. M. Lobato, Iberoamericana, Madrid, 2004, p. 563. 
para una típica comedia de capa y espada. Su punto de partida es la visita de dos damas sevillanas sin más acompañamiento, pero con mantos completos como credencial de respetables ${ }^{17}$. Son doña Urbana y su sobrina Laura, libres ambas y asiduas de aquel Arenal, donde coquetea la más joven con el capitán Fajardo y al parecer están hechas a cierto grado de vida galante, aunque en absoluto profesionales ni busconas de la misma. Ven por casualidad a un joven caballero llamado don Lope que acaba de llegar de la lejana y, por lo adusta, incongrua Medina del Campo. Viene fugitivo de cierto duelo por amores en el cual cree haber muerto a su adversario y pretende pasar a Indias, pero encuentra que la flota acaba de partir y su capitana, en que pensaba embarcar, está ya en Bonanza. Hay que darse prisa a alcanzarla, ajustando una barca para ir a buscar un piloto en Triana, pretexto para vivaz escena de regateo por el precio, muy inflado en días de flota. El tira y afloja es contemplado por Laura, que instantaneamente se enciende en llamas por don Lope, quien, de momento y por mor de su desengaño, no presta atención a su manifiesto interés. Del todo lanzada y sin consultar con su tía, no duda ella en subir a la misma barca, pues se muestra harto dispuesta a "ponerle un cebo / con que él me vaya a buscar" (I, 367) al escarmentado medinense. Su eficaz estrategia sabe cómo aprovechar el escaso espacio de la enramada navichuela, porque el Guadalquivir es también

17 La diferencia a su favor queda de manifiesto por el atuendo femenino imperante en el no menos sevillano patio de Monipodio: “...cubiertas con medios mantos de anascote, llenas de desenfado y desvergüenzas por donde...conocieron que eran de la casa llana" (Novelas ejemplares, ed. J.B. Avalle-Arce, Castalia, Madrid, 1982, t. 1, p. 248). Lope no ha querido ser más explícito y su texto omite por entero informar acerca del estado sociofamiliar de ambas mujeres, de situación sin duda acomodada aunque carentes, al parecer, de apoyos masculinos o de cualquier otro orden económico. Importante que, al menos, Laura no olvide proclamar "que soy / noble, y que erré como noble" (III, 395) pues, con razón o sin ella, la han llamado allí una "sota" (I, p. 366). Aunque Urbana se llame tía y de alguna más edad que Laura, no aparece investida en el típico papel de dueña, celestina ni carabina y al final sorprende por casar con Toledo, criado de don Lope. Por lo demás, la demografía sevillana incluía en estas fechas una alta proporción de mujeres que vivían por sí solas, igual que se perfila allí el caso; véase J. Sentaurens, "Quelques remarques à propos des classes sociales de Seville dans la 'comedia' lopesque", Dramaturgie et société aux XVI et XVII siècles, éds. J. Jacquot et E. Konigson, CNRS, Paris, 1968, pp. 31-45. Delicuescente, LuIS Del Rey Caballero, La mujer sevillana en la obra de Lope de Vega, Ayuntamiento, Sevilla, 1975. 
un jardín del amor en el que logra sin dificultad su objetivo, de modo que cuando vuelven a pisar el Arenal son ya pareja amartelada ${ }^{18}$ y con el hasta allí fugitivo prendado por "Aquel donaire andaluz / ¿a quién no causara antojos?” (I, 375). Un típico quid pro quo determina después que don Lope sea allí asaltado al atardecer por cuatro embozados, tan desalmados como, a la vez, bromistas a lo sevillano en su trato. Es el más extenso y logrado de tales despuntes complementarios, que podría figurar como muestra antológica del soberano dominio del poeta en su manejo del ocasional resorte escénico. Los semi-jocosos agresores dejan a don Lope herido sobre la arena, lo cual es encubridora excusa para que Laura se apodere por las buenas de él, llevándoselo a su casa dizque para curar sus heridas, sin atender al asombro escandalizado de su tía: "Mira que es libertad esta / contra tu honor y quietud" (I, 377), pero sin que el atrevimiento se halle destinado a suscitar ningún problema. El Arenal hispalense ha hecho, pues, una de las suyas y la comedia se halla en plena marcha.

Don Lope tiene bajo las manos de la linda sevillana una convalecencia de varios meses, lo cual hace murmurar que ella le prodiga, a título de supuesto primo, los mismos saludables cuidados de Angélica con Medoro. Mientras tanto, la dama implicada en el asunto aquel de Medina del Campo y llamada Lucinda, ha escapado a Sevilla para buscar al mismo don Lope, a quien amaba de seis años atrás. No sabe de su paradero, a excepción de una vaga noticia de hallarse en la ciudad, ni si está vivo o muerto, y su estado de ánimo responde a una desesperación integral:

...Perdida

ya la esperanza en mi mal.

sólo mi fortuna sigo,

${ }^{18}$ El mismo eficaz señuelo, que se ve era usual y propio de la diversificada galantería en el Guadalquivir, se repite en Los peligros de la ausencia, comedia de hacia 1615-1618. La barca del Guadalquivir es también elegida lugar de cita por una dama en la comedia de Lope Los peligros de la ausencia (1615-1618). En sentido más amplio, Manuel Cornejo, "Algunas funciones del espacio sevillano en las comedias de Lope de Vega", Memoria de la palabra. Actas del VI Congreso de AISO, pp. 564-565. Abundan los testimonios pictóricos y literarios "que abordan alguna escena de excursionistas bajando... incluidas las de damas y caballeros en funciones de amantes furtivos" (J.M. Caballero Bonald, Sevilla en tiempos de Cervantes, p. 77). 
como el que en el mar incierto

no tomando el propio puerto

tomara el puerto enemigo (II, 377).

Como se sabe, se trata de una situación teatral muy común, en que la mujer atrapada en algún caso de honor suele correr su aventura vestida de hombre ${ }^{9}$, pero aquí la feliz novedad es que Lucinda, sin duda por entrar en carácter con Sevilla, lo hace "en hábito de gitana, muy bizarra" (II, 376) ${ }^{20}$ que sabe la favorece mucho, pero que a la vez supone una dificultad imposible en cuanto a modales y lengua para un tal Florelo, su oportuno cicerone sevillano:

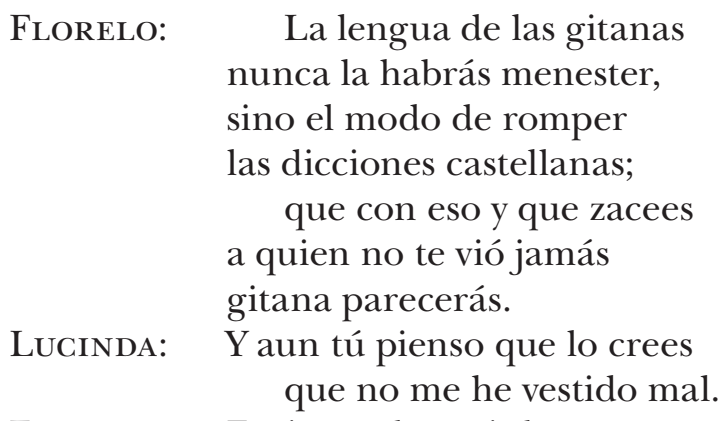

Florelo: Estás mucho más hermosa.

A ver di,

LUCINDA: Cara de rosa...

FLorelo: ¡Es su lengua natural!

¡No he visto tal en mi vida! (II, 377-378).

El arriesgado estreno de la espúrea identidad acaece, tal como debía ser, en el Arenal, llevada Luinda de la mano por

19 J. Homero Arjona, "El disfraz varonil en Lope de Vega”, BHi, 59 (1937), 120-145. Sobre sus orígenes y tipología, Carmen Bravo Villasante, La mujer vestida de hombre en el teatro español, Revista de Occidente, Madrid, 1955. El travestismo femenino en relación con el conflicto de honor, estudiado por Yvonne YARbro-Bejarano, Feminism and the honor plays of Lope de Vega, Purdue University Press, West Lafayette, IN, 1994; María Carrión, "Woman in Breeches", en Marriage, theatre and the law in Early Modern Spain, University of Toronto Press, Toronto-Buffalo-London, 2010, pp. 125-147.

20 Acerca de los gitanos en esas difíciles fechas, Antonio Domínguez Ortiz, "Documentos sobre los gitanos españoles en el siglo xvir", Homenaje a Julio Caro Baroja, Madrid, 1978, pp. 319-326. Sobre la dura política de Felipe III, con las pragmáticas anti-gitanos de 1611 y 1619, M. Helena Sánchez, Los gitanos españoles, Castellote, Madrid, 1977, pp. 88-90. 
este mismo Florelo como a escenario donde todo se vuelve posible y hasta "se vieron los que en su vida / se pensaron ver" (II, 377). Y es además un cierto día grande en que, debido a la llegada de las galeras de Italia, salen a recibirlas todas las mujeres de Sevilla ${ }^{21}$. Se acerca Lucinda a decir la buenaventura a los susodichos militares, en los que comienza por causar muy halagüeña impresión, si bien el capitán Castellanos no se emplea mucho con gitanas, pues aunque "hay de aquestas / algunas limpias y hermosas" (II, 379), les encuentra el grave defecto de profesar inquebrantable fidelidad a sus maridos. Ocurre como caso imprevisto que a su colega el capitán Fajardo le acaban de afanar una bolsa con dinero y ambos creen que ha sido por complicidad de Lucinda, por lo cual pretenden desnudarla y ella se ve obligada a revelar su identidad de mujer castellana y principal (el trance se presta a singulares efectos escénicos) ${ }^{22}$.

No es cosa de seguir hic et nunc los diabólicos enredos de la acción. Baste decir que Lucinda triunfa plenamente como perfecta gitana en la bizarra escena (también obligada) de tenso encuentro con su rival Laura, en uso del artificio no menos canónico de "engañar con la verdad" ${ }^{23}$, que en este caso es la

21 Aunque no se dispone de mucha información, es dato fehaciente. Según el cronista local Francisco de Ariño, un día de agosto de 1602, "Habiendo en el río de Sevilla, diecinueve galeras españolas e italianas, hubo una gran revuelta, que se dieron cuatro muertes, que los italianos mataron, y todo este alboroto lo hicieron cuatro españoles, porque encontraron los estranjeros italianos que venían de las viñas cargados de uvas" (Sucesos de Sevilla de 1592 a 1604, pp. 112-113).

22 El exhibicionismo femenino fue un destacado artificio del teatro clásico, correspondiendo en ello la primicia a Cervantes, inevitablemente seguido en esto por Lope, como señala STURGIS A. LEAwITT, "Strip-tease in Golden Age drama”, Homenaje a Rodríguez Moñino, Castalia, Madrid, 1966, t. 1, pp. 305-315. De ahí las frecuentes condenas de las comedias como provocación a lujuria en boca de moralistas como el P. Juan de Mariana en su De Spectaculis (Colonia, 1609) con su andanada contra el escándalo de las bellas actrices que, si no desnudas como en tiempos del paganismo, se mostraban en escena "tenuissimas vestibus indutas" (cap. 8, p. 143). Desarrolla la cuestión Rina Walthaus, "«Para pretendida, Tais. Y en la posesión Lucrecia”. Erotismo y castidad femenina en algunas obras del Siglo de Oro", en La creatividad femenina en el mundo barroco hispánico. María de Zayas. Isabel Rebeca Correa. Sor Juana Inés de la Cruz, eds. M. Boss et al., Reichenberger, Kassel, 1999, t. 1, pp. 193-208.

${ }^{23}$ G.T. Northup, "The rhetorical device of deceiving with the truth", Modern Philology, 27 (1929-30), 487-493. Figura retórica de origen clásico, es muy recomendada por Lope en su Arte nuevo, donde achaca su paternidad a Miguel Sánchez, estudiado por Stefano Arata, "Un'opera sconosciuta di 
historia amorosa de ambas, que sólo ella conoce por su doble vertiente. Lucinda extrema el papel cuando despliega para la otra su bien ensayada identidad gitana:

...Dad por Dios,

cara buena, cara hermosa,

noble, honesta, vergonzosa,

que el cielo os guarde a las dos,

algo a esta pobre gitana ${ }^{24}$ (II, 383).

Con discretísima astucia, sabe ganar la confianza de la amante hispalense y para la cual calumnia a don Lope, denunciándolo como gitano disfrazado y reo de toda suerte de crímenes, entre ellos el de bígamo por partida no doble sino cuádruple y evadido además de galeras, que para aquella noche se propone desvalijar la casa de bienhechora y llevársela además por la fuerza. Y claro que es todo trampa urdida para recuperar a don Lope, entregándolo preso a una corrupta justicia del rey que es muy fácil de comprar, igual que otro género cualquiera, en el famoso Arenal de Sevilla.

El nudo de la obra viene a cuenta de la llegada a aquella playa de la víctima del duelo con don Lope, un hidalgo de nombre Alberto, que trae de Medina del Campo carta de otro capitán amigo para presentación a su colega Fajardo. Lo hace el recién venido sediento de venganza y todavía apasionado de Lucinda, pero topa en el Arenal con los dos caballerosos militares, que le hacen ver la futilidad legal de su proceder en papel de

Miguel Sánchez «El Divino»: «La tragicomedia 'La desgracia venturosa'»", CuN, 45 (1985), 125-140. Origen en Terencio (Heautontimoroumenos) según Irving P. Rothberg, "Algo más sobre Plauto, Terencio y Lope", Lope de Vega y los orígenes del teatro español. Actas del I Congreso Internacional sobre Lope de Vega, Edi-6, Madrid, 1981, pp. 61-65. Inserta también El arenal de Sevilla en la comedia de enredo, sus transgresiones en esto ocurren fuera del ámbito escénico, como observa José Roso Díaz, "Las estrategias del engaño para el desarrollo de la acción en la obra dramática de Lope de Vega", ALV, 3 (1997), p. 175. Como dictamina José Bergamín, "el engañar con la verdad, es la cosa, es la causa, del teatro lopista" (Mangas y capirotes. España en su laberinto teatral del XVII, Editorial Plutarco, Madrid, 1973, p. 214).

${ }^{24}$ La escena de la buenaventura que se sigue no desmerece de la de Preciosa de La gitanilla en Cervantes, socialmente agresivas ambas si bien la una fundada en celos y la otra en despecho por lo mezquino del trato a que se ve sometida en el Madrid pudiente. Francisco Márouez Villanueva, "La buenaventura de Preciosa", NRFH, 34 (1985-86), 741-768. 
agraviado. Cambia con esto o simplemente desaparecerá de golpe el problema, pues nada impide que tras algunas vueltas y revueltas haga Alberto las paces con don Lope. La fugitiva Lucinda, fracasada a pesar de su magistral adopción del habla, maneras e indumentaria del estereotipo gitano, tendrá que conformarse con aceptar por esposo al fiel Alberto, que al fin y al cabo sigue adorándola. Y los felices amantes que hacen don Lope y Laura hasta se brindarán como padrinos hispalenses de los recién llegados para la boda, nunca antes prevista y ahora tan fácilmente agenciada.

Comedia, pues, como se ha dicho, al uso de capa y espada, pero única y ainda mais. Figura allí por de pronto el despliegue "documental" a noticia del Arenal de Sevilla, en anticipo o preludio, no tan remoto, de la couleur locale romántica (Mérimée) y de la tranche de vie del naturalismo decimonónico (Zola) si bien, a diferencia estilística de los cuales, se prodigan exquisitos diálogos a la altura de una elegancia natural, saturada de ingenio y autenticidad popular de la más fina ley. Sólo que más allá de eso, la arenosa explanada constituye una imagen funcional ${ }^{25}$ válida para toda la obra en cuanto aplicación o trasunto verista del fluir cuotidiano y tensiones vitales de la urbe andaluza. El Arenal en principio no ofrece ninguna ejemplaridad, ni menos puede llamarse un lugar recomendable: cunden allí fragilidades, delitos, corrupción y picardía (empezando por las amorosas) pero no sucede nada irreparable y su discurrir no llega a ser nunca amenazador ni siniestro. Su acento, por el contrario, es lúdico y en todo caso neutro, quedando por completo atrás el mundo de la prédica moralizante y del daño irreparable. Las cosas fluyen por su propio cauce, tienden a arreglarse por sí solas y la sangre, también a la letra e incluyendo la del protagonista, no llega nunca al río. La obra transcurre bajo una semiología connotativa y literariamente sinergística de confusion, máquina, enredo, blandura, quimera y similares. Lo hace en extensión sincrónica de lo movedizo, cambiante y amorfo del básico lexema arena y sus afines, culminando en mudanza, que allí actúa asimismo como concepto y vocablo clave, en extensión popularizada del proverbio clásico Arena committere semine. Es el Lope de Vega que en pleno derecho cabe llamar shakesperiano, quien recoge esta imagen de base para toda la obra

25 Casos similares alegados por DAvid. M. Gituitz, La estructura lírica de la comedia de Lope de Vega, Albatros, Valencia, 1980. 
conforme al despliegue de uno de sus grandes momentos en el lirismo analítico ${ }^{26}$ de un espléndido soneto:

Sembrando en tu Arenal mis esperanzas ¡oh Sevilla!, ¿qué fruto será el mío, que ni del llanto bastará el rocío, ni del ligero tiempo las mudanzas?

¡Oh tú, que del ocaso al norte alcanzas pensamiento menor que el desvarío! si en el arena siembras de este río, tu cosecha será desconfianzas.

Si comparas tu arena con mis males tú, ni la Libia, de montañas llena, tenéis bastante copia de arenales.

¡Oh, principio terrible de mi pena! Si en él son las arenas desiguales, ¿qué fin espero de sembrar tu arena? (I, 375).

Lo que no hay, pues, en el Arenal de Sevilla es nada inconmovible ni perenne, porque todo resulta allí contingente, efímero y movedizo, lo mismo en lo relativo a sentimientos y personas que a noticias y cosas, en paralelo con el continuo entrar y salir de sus naves y el azacanamiento de sus aprestos militares. Al otro extremo, Lucinda se muestra anclada en una idea fija, según la cual "En esta tierra jamás / echará mi amor raíces" (III, 377), lo cual es muy cierto porque ya lo había hecho sobre un suelo muy diferente. Y es lo que profundiza en el soneto que, en aras de economía estructural, declamará allí muy pronto. Su temerario, gitanesco arrojo, responde todavía

26 Diego Marín, Uso y función de la versificación dramática de Lope de Vega, Castalia, Valencia, 1962, pp. 50-54. El soneto como supremo recurso de la expresividad escénica de Lope "sirve idealmente para un examen de conciencia, para revelar ambivalecias, luchas internas, incertidumbres, como vehículo de introspecciones atormentadas...", en acierto de JosEPH H. Silverman, "Personaje y tipo literario: el converso", El personaje dramático. Actas de las VII jornadas de teatro clásico español (Almagro, 1983), Taurus, Madrid, 1983, p. 256. Para el soneto como texto narrativo en Lope, Antonio García Berrio, "Construcción textual en los sonetos de Lope de Vega: tipología del macrocomponente sintáctico", RFE, 60 (1978-80), p. 37. Para el soneto y tensiones entre los personajes, Peter N. Dunn, "Some uses of the sonnets in the plays of Lope de Vega", BHS, 33 (1957), 213-222. Caso especial estudiado por Marie RoIG Miranda, "Los nueve sonetos de «El perro del hortelano" de Lope de Vega", El Siglo de Oro en escena. Homenaje a Marc Vitse, eds. O. Gorse y F. Serralta, Presses Universitaires du Mirail-Consejería de Educación de la Embajada de España en Francia, Toulouse, 2006, pp. 893-206. 
a la estampilla de Medina del Campo, y es mero disfraz de tópicas galas verbales que, como pretendida gitana, ha de pedir prestadas (si bien por poco tiempo) al de siempre doloso Nilo:

Nace en Egipto el fiero cocodrilo, que al peregrino llama en voz humana, con que a su cueva y boca el paso allana del que ha seguido su engañoso estilo.

No lo es el llanto que por ti destilo, ni porque de tu vida soy tirana, que, aunque traigo vestidos de gitana, nací en Medina, y no ribera el Nilo.

Peregrino del alma que te adora: Lucinda soy, que, sin ventura vengo a decir a los hombres la ventura.

Dame, dame esa mano vencedora; que si ventura de tomarla tengo, su palma la victoria me asegura (II, 378).

En alarde de la misma sabia carpintería interna, es también la falsa apariencia que atrae a su juego el sentido profundo de la acción de capa y espada, tendida entre los dos polos geográficos de Medina del Campo frente a Sevilla. Conoció la primera un conflicto de celos y amor que impidió el concertado matrimonio de Lucinda con Alberto, puso en peligro la vida de éste y convirtió a don Lope en un transitorio desamorado misógino. En conjunto, pues, un negativo tinglado que sin el menor esfuerzo desintegran las arenas del lánguido Guadalquivir, con su arrastre del binomio Lucinda-Alberto cual pareja acorde (por distinto motivo) en el proyecto de una sangrienta y precalderoniana venganza de honor: "Que intentaste injustamente / tu deshonor con el mío" (II, 385) según reprocha ella a su primer amor don Lope. Con lo que nadie ha contado sobre las tablas es con la nueva perspectiva que induce el simple hecho de pisar aquellas felices playas. El nudo a desatar es que, para su análisis bajo luz de una lógica hispalense, el conflicto larvado en Medina del Campo era la circunstancia trivial de un malentendido en torno a la posesión no siquiera de la dama, sino de un retrato suyo (imagen a su vez de común apariencia) ${ }^{27}$.

27 M.A. Peyton, "The «Retrato» motif and device in Lope de Vega", RNo, 4 (1963), 51-57. Sobre su fondo neoplatónico, E.G. ERDMAN, "An additional note on the Retrato motif in Lope", RNo, 5 (1964), 183-186. El retrato de la amada medinense quedó manu militari en poder de don Lope, quien lo 
Quedaba pendiente la responsabilidad por el desafío, para la cual la jurisprudencia del duelo que enjuician los capitanes Castellanos y Fajardo no hallaba culpables a ninguna de las partes. Lo mismo también respecto al presunto deshonor de que inicialmente se considera alcanzada Lucinda, pero sin otro fundamento que lo monumental de sus celos. Y como ley de validez suprema en esto del honor, la primera consideración (en boca de la ahora convencida Lucinda) es reclamar en tales asuntos un poco de reflexiva cordura. Nada pues de poner las cosas peor que estaban, y es hora ya de recapacitar y alejarse de necios empecinamientos. ¿Acaso el honor mismo no es todo él una necedad?:

Ya no hay rastro en mí de amor.

El honor fue el que quería que venciese mi porfía, que es siempre necio el honor;

porque el querer remedialle resulta en mayor deshonra; que las voces de la honra no se han de dar en la calle ${ }^{28}$.

La transformación de Lucinda es ahora completa en lo tocante a habla y modales de no fingida gitana ${ }^{29}$. Los aviesos cocodrilos acechan, pues, en Medina del Campo y su menguado Zapardiel, pero no en el que Góngora llamaba "gran rey de Andalucía" ${ }^{30}$. Aparte del documento "a noticia", sus arenas jue-

cede sin reparo a Laura, con expreso menosprecio, pues “...para mí pintada es nada, / y viva no tiene ser" (I, p. 374). En la escena final el sevillanizado amante lo devuelve a su legítimo dueño Alberto como alarde gestual de paz y reconciliación.

28 III, 390. Para el tema del honor y Lope, para quien "ni en su vida ni en su obra fue nunca un disidente", se dispone, en particular, de AmADo Alonso en su admirable artículo, "Lope de Vega y sus fuentes", BICC, 8 (1952), 1-24. Lope es ambivalente hasta un punto de contradicción entre su crítica del honor en Las ferias de Madrid y el respaldo de su venganza en Los comendadores de Córdoba; véase Donald R. LARSOn, The honor plays of Lope de Vega, Harvard University Press, Cambridge, Mass.-London, 1977, pp. 28-37. Para otras invectivas de Lope contra el honor, Alix Zugkerman-Ingberg, El bien más alto. A reconstruction of Lope de Vega's honor plays, University Presses of Florida, Gainesville, 1984.

${ }^{29}$ Observación de K.E. Weston, "Change and essence in Lope de Vega's «El arenal de Sevilla»", MLN, 86 (1971), p. 217.

${ }^{30}$ Luis de Góngora y Argote, soneto "A Córdoba”, Obras completas, p. 455. 
gan así como piedra de toque para el extremo contraste entre la estrecha villa castellana y la anchura de la urbe hispalense, a modo de reflejado acorde en devaluación de la venganza de honor $^{31}$. Lo que allí era severidad, rigor y dureza, es en esta otra flexibilidad, blandura y joie de vivre en el perpetuo movimiento de su tumultuoso Arenal. Hombres y mujeres hechos a vivir bajo una pétrea sociología de coacción acumulada de siglos, aprenden a conocerse a sí mismos en la vividura despreocupada de aquel otro escenario de privilegio, donde las leyes se acomodan a la instancia azarosa de las personas y no al contrario. Dicho en otras palabras, se da la oposición entre un ethos de abstractas apariencias y otro de perentorias realidades humanas. Frente al rígido amor canalizado sin realización durante años entre Lope y Lucinda, el de éste y Laura es un surtidor que no sólo brota irrestañable de aquellas mismas arenas, sino prevalece además a prueba de mentirosas apariencias (retrato y disfraz gitano) lo mismo que del ataque frontal de la agraviada celosa. Y siendo además de notar que la actitud del capitán Fajardo, desde siempre enamorado también de la inflamable Laura, muestra la sensatez de asumir sin queja su adversidad en amor y no ir, estoicamente, contra lo imposible:

Como quiera yo me siento

razonable de mi mal:

sembré amor en arenal, vino agosto, y cogí viento (III, 387).

Lucinda y Alberto vinieron por su parte al Arenal para restaurar su honor y lo consiguieron de consuno mediante la receta sencillísima de reconocer, bajo la elocuente persuasión de dicho espacio, la irrealidad del mismo. En Sevilla las cosas son distintas y no se comienza, ni menos aún termina, con ningún atropellado echar por la tremenda. Don Lope, a su vez, cura de golpe en el Arenal de la vulgar misoginia que le ahorrará

31 No es del todo cierto que Lope esté siempre con "la superioridad de las instituciones sociales sobre las pasiones del individuo" (JEsús Gómez, Individuo y sociedad en las comedias de Lope de Vega, Universidad Autónoma de Madrid, Madrid, 2000, p. 131). Como allí mismo se alega a continuación, proyecta a veces también Lope la excusa semicómica del deshonor secreto, salvadora en su obra de más de una mujer culpable (ibid., p. 132). Similar planteamiento de Charlotte Stern, "Lope de Vega, propagandist?”, $B C$, 34 (1982), 1-36. 
un viaje a Indias y, ganado para siempre de la mullida acogida de la tierra, no retorna a su Valladolid natal. Los dos capitanes, por último, tendrán que ir a pelear donde los manden, pero confiesan su escaso deseo de abandonar Sevilla, porque la hermosura de sus mujeres es a la letra "río de olvido" (I, 372) harto capaz de sobreescribir cualquier tipo de viejas páginas sentimentales. El revuelto, hirviente Arenal no cuenta en absoluto como una cour des miracles, así como tampoco ninguna escuela de hampa ni foco de mala vida pero, sobre todo y a pesar de la amistad que a la sazón prospera en Sevilla entre Lope y Mateo Alemán ${ }^{32}$, se halla a mil leguas de la rígida cosmovisión picaresca $^{33}$, en que nunca incidió el madrileño. El Arenal, frente a ella, se configura como incontrolado experimento de un vivir a inédita escala el factor económico que estalla incontenible por todas sus costuras, desde las de la bolsa hasta las de la poesía y el sexo. La desusada pero no loca experiencia hispalense es así bienhechora, espontánea y sello garante de una transformación en el clásico sentido retórico de una tropelía ${ }^{34}$ integral, según mudanza que reconoce, modesto y lúcido, el ahora satisfecho don Lope:

Todo en mudanzas consiste; no te cause maravilla; que yo me mudé en Sevilla del que en Medina me viste (III, 390).

Lo mismo que, paralelamente, la arrojada Lucinda pasa a recoger velas con su conversión a una gramática sentimental mucho más circunspecta en materia de amor y de celos. Y no puede menos de hacerlo en línea con la perspectiva racionalista y hasta tocada de un puntillo de erótico cinismo, que explaya en el tercero y último de los sonetos en que Lope proyecta el sondeo profundo de la obra:

32 Mateo Alemán declaraba en esos días como testigo falso en asuntos legales de Lope. Véase JoaQuín de Entrambasaguas, Vivir y crear de Lope de Vega, CSIC, Madrid, 1946, p. 323.

${ }^{33}$ Cerrazón de Lope al fenómeno picaresco, en Gonzalo Sobejano, "Lope de Vega ante la picaresca", Actas del VII Congreso de la Asociación Internacional de Hispanistas, Bulzoni, Roma, 1982, pp. 987-995.

34 Bruce W. WARDropper, "La eutrapelia en las «Novelas ejemplares» de Cervantes", Actas del VII Congreso de la Asociación Internacional de Hispanistas..., pp. 163 y 165 . 
Alarga riendas, pensamiento loco, si descansa el amor con la venganza; que cuando entre los males hay mudanza, yo pienso que los males duran poco.

Si con tus alas el remedio toco, no se anegue en la pena la esperanza; logre su pretensión la confianza, si al cielo con mis lágrimas provoco.

Mitigad, corazón, vuestros desvelos, esforzad el valor de mis porfías mientras os miran los piadosos cielos;

porque con celos estorbar dos días que no se gocen los que dan los celos basta para templar las penas mías (III, 393).

Y lo mismo Lope, el poeta, que su homónimo personaje, han asimilado a fondo la lección del pragmático laissez faire de Sevilla, que es también una ciudad del desengaño, sólo que no del ascético ni del que hemos dado en llamar barroco, sino del opuesto de endurecer artificialmente la vida, como se estila allá por Castilla la Vieja. Escrita en la primavera o más bien verano de 1603, El arenal de Sevilla ${ }^{35}$ rebosa la satisfacción de su autor al cabo de meses de avecindamiento hispalense e intensa actividad creadora (El peregrino en su patria), en pecaminosa luna de miel con la actriz Micaela de Luján, sin causar por ello escándalo ni sufrir, que sepamos, mayor provocación de nadie ${ }^{36}$. Las

35 Fechada primeramente como de 1601-1603 por AdAlbert Hämel, Studien zu Lope de Vegas Jugenddramen, Verlag von Max Niemeyer, Halle a Saale, 1925, p. 60. Basado en el cronista L. Cabrera de Córdoba sobre nombramientos militares, la fijaba escrita entre el 28 de febrero y el 17 de mayo de 1603 J.H. ArJona, "Apunte cronológico sobre el «Arenal de Sevilla»", HR, 5 (1937), 344-346. Perfilado en lo esencial por el estudio más detenido de George Irving Dale, “«Periodismo» en «El arenal de Sevilla»”, HR, 8 (1940), 18-23. Sólo la segunda de dichas fechas (mención simultánea de los mandos navales para galeras de España, Sicilia y Nápoles) determina un firme post quem para El arenal de Sevilla.

${ }_{36}$ La presencia de Lope electrizó el panorama poético sevillano en un momento de transición. La arrogancia y dudosa reputación del Fénix y, en especial, la buena acogida del alto círculo social de poetas de la ciudad (grupos o academias de Arguijo y de Pacheco) produjo una andanada de sátiras por parte de otros menos afortunados y, sobre todo, un soneto escatológico de marcada factura (hay que reconocer) cervantina. Tras lo cual es preciso admitir que nada de aquello tuvo graves consecuencias ni pasó de cierta hilaridad al estilo de la tierra, sin que se conozca ninguna particular reacción ni queja por parte de Lope, más dispuesto que otras veces a no perder los 
arenas del río benefactor resultan, no es preciso decir, ideales para encubrir humanas flaquezas y la accessible ciudad, "puerta para todos llana" (I, 370) ofrece remedios para cualquier aflicción, motivo por el cual no se olvidará Lope de mencionar por boca de Laura el monasterio de dicha advocación que, a la entrada y salida del puerto sevillano suelen saludar los viajeros en su ida o vuelta de Indias:

Los Remedios es su nombre:

remediad ese rigor,

y cree que con amor

no pasa a las Indias hombre (I, 373).

Por encima de lo anecdótico de las tablas y su activo mercado, el teatro de Lope ofrece, sobre todo en su etapa inicial, una fuerte preocupación por la identidad oculta, reprimida o vacilante como faceta problemática de la España a su alrededor ${ }^{37}$ y donde no todos podían decir, como don Quijote, "yo sé quien soy" $(\mathrm{I}, \mathrm{V})^{38}$. El legado imborrable de una historia multicultu-

estribos. El episodio sevillano quedó ya documentado por José M. AsEnsio, Cervantes y sus obras, Barcelona, 1902, pp. 266-291. Vuelve al mismo JoAQUín de Entrambasaguas, Vida de Lope de Vega, Labor, Barcelona-Madrid, 1936, pp. 157-172, con texto del discutido soneto en p. 163. Posteriormente, DAvid Castillejo, "Diego Díaz, marido de Micaela de Luján”, BRAE, 64 (1984), 257-295.

37 Richard F. GLENN, "The loss of identity: Towards a definition of the dialectic in Lope's early drama”, HR, 41 (1973), 609-626. Sobre el sentido profundo de la ubicuidad de máscaras y disfraces en Cervantes, José M. Martín Morán, "Los velos de la identidad en el «Quijote»", Atti della sesta giornata cervantina, eds. D. Pini y J. Pérez Navarro, Unipress, Padua, 2000, pp. 197-217; STEven Hutchinson, "El valor de amar: identidad y dimensión pública del amor", Actas del III Congreso Internacional de Cervantistas, Palma, 1998, pp. 179-185; SAlvador J. FaJARdo, "Eros e identidad: «Don Quijote» II, 30-32”, Cervantes. USA, eds. G. Dopico Black y F. Layna Ranz, CSIC-Ediciones Polifemo, Madrid, 2009, pp. 487-515.

38 Cuestión fundamental a partir de la profunda exégesis de Miguel DE Unamuno, Vida de don Quijote y Sancho, en Obras completas, Afrodisio Aguado, Madrid, 1950, t. 4, pp. 134-137 (original, 1906). Estudios de Agustín BASAVe Fernández del VAlle, Filosofía del "Quijote". (Estudio de antropología axiológica), Espasa-Calpe Mexicana, México, 1949, pp. 264-268; Amancio BolAÑo E Isla, "La voluntad de ser en don Quijote", ALM, 1 (1961), 99-112; E.C. RILEY, "Who's who in «Don Quixote» or an approach to the problem of identity", MLN, 81 (1966), 113-130; Antonio Romero MÁrquez, "Sobre el 'yo sé quién soy' (una lectura del capítulo V del «Quijote»)", CuH, 144 (1986), 99-112; Stephen Gilman, The novel according Cervantes, University 
ral y trirreligiosa, unida al trauma de los nuevos tiempos que tan vigorosamente proyectaba aquel suelo de Sevilla, era lógico indujeran perplejidad en no pocas conciencias. Debemos a Lope un documento tan inquietante como su novela de $L a$ desdicha por la honra ${ }^{39}$, en cuyo surco anticipado cabría encajar el reajuste (esta vez feliz) de ambas parejas en el Arenal de Sevilla, cual idónea cabecera de una nueva instancia taxonómica como "comedia de identidades" para un avance significativo en el conocimiento de la obra dramática del Fénix ${ }^{40}$.

Si cuanto antecede se ciñe a aspectos personales y hasta íntimos del discurso sevillano de Lope, la comedia de El arenal de Sevilla ofrece también otro de signo correlativo en lo que toca al enfrentamieto allí de Sevilla-Medina del Campo, la famosa villa comercial castellana, floreciente en otro tiempo, pero ya bastante apagada para aquellas fechas. La disyuntiva esbozada no es de primera intención otra que la supuesta por un pasado frente a un presente, tras la cual se perfila el tirón de la dualidad Castilla-Andalucía en materia de estilos vitales. No se daba

of California Press, Berkeley-Los Angeles-London, 1987, pp. 92-94; JuLIÁN Marías, "Yo sé quién soy", Cervantes clave española, Alianza Editorial, Madrid, 1990, pp. 118-130; Charles Oriel, "'Yo sé quién soy'. How Don Quijote does things with words", Cervantes, 29 (2009), 53-83.

39 Es de justicia aún pendiente el reconocimiento del conflicto allí abordado acerca de los moriscos expulsos, pero con resonancia ineludible para todo español consciente y ante la cual no se atreve Lope a dar el último paso, muy al contrario de Cervantes con su Ricote en la Segunda parte del Quijote. Véase Marcel BAtaillon, "«La desdicha por la honra»: génesis y sentido de una novela de Lope", en Varia lección de clásicos españoles, Gredos, Madrid, 1964, pp. 373-418, que acerca además el problema a comedias de Lope como La villana de Getafe y El galán de la Membrilla. Para la misma cautela de su criterio acerca de éste y otros graves asuntos políticos, Jorge CHECA, "Lope de Vega ante la cuestión morisca. Ideología y juego literario en «La desdicha por la honra»", $A L V, 7$ (2001), 7-24. Sobre la evolución de la crítica acerca de la ideología de Lope, más compleja de lo que se venía creyendo, Janet B. Norden, "Lope de Vega's use of discretion: An indication of a change in Spanish thought", BC, 39 (1987), 99-114. Lo mismo CATHERINE Swietlicki, "Lope's dialogic imagination: Writing other voices of 'Monolithic Spain'”, BC, 40 (1988), 205-226.

40 Sobre la necesidad de una clasificación más a fondo de las comedias de Lope, Frida Weber de Kurlat, "Hacia una sistematización de los tipos de comedia de Lope de Vega", Actas del V Congreso Internacional de Hispanistas, eds. M. Chevalier et al., Instituto de Estudios Ibéricos e IberoamericanosUniversité de Bordeaux, Bordeaux, 1977, t. 2, pp. 867-871; Felipe B. PedrAZA, Lope de Vega. Vida y literatura, Universidad, Valladolid, 2008, pp. 122-124. 
en el momento ningún abierto conflicto, pero aun así alza su voz el contraste entre la severidad estática del norte castellano frente a la dinámica vivaz de la franja meridional del reino. Lope se está de hecho interrogando acerca de una inmensa Monarquía que, con pies cada vez más de barro, se obstina en dar la espalda a las tierras del sur, en completa indiferencia a su realidad y a sus promesas ${ }^{41}$, esto es, a la nueva vida que palpita y junta a España y las Indias sobre el Arenal de Sevilla. Lope fue siempre consciente del problema, que a veces proyectó en la imagen de una pugna de río a río entre el Tajo, de raíz tan castellana, y el alienante Guadalquivir "morisco" 42 . No es, en absoluto, cosa de exagerar dicha tensión en el sentido de una reivindicación regionalista al modo actual. Y nada por tanto de pugnas ni de protestas, aunque sí de afirmar cómo un Lope sevillanizado transpira la sensibilidad a flor de piel con que palpa el alejamiento de un duro centralismo aferrado al mito castizo-castellano. Y frente a ella la pujante desigualdad que

41 Ofrece sobre este aspecto sus reflexiones Jean-Marc Pelorson, Les letrados juristes castillans sous Philippe III. Recherches sur leur place dans la société, la culture et l'état, Université de Poitiers, Le Puy-en-Velay, 1980. Así la especie de interior "imperialismo castellano" (p. 117) y esclerosis del centro frente a la vitalidad andaluza (p. 45l) como desequilibrio entre centro y periferia (p. 478). Buen ejemplo, entre muchos posibles, la preferencia oficial para altos cargos de letrados procedentes del reino de León y Castilla la Vieja junto a olvido de extremeños y andaluces, que sólo hallan vía libre en el acceso a las armas, según documenta Janine FAYARD, Les membres du Conseil de Castille à l'époque moderne (1621-1746), Droz, Genève, 1979, pp. 221-232.

${ }^{42}$ Lope se complace, con mediocres versos juveniles, en insinuar falta de limpieza y sobre todo de la de sangre, así como juegos sobre la oscura piel de las sevillanas (antiguas moras) entre otras pretendidas burlas (José M. DE Cossío, "Notas a romances", Studia Philologica, Gredos, Madrid, 1960, t. 1, pp. 413-429). Antonio Gallego Morell, "El río Guadalquivir en la poesía española”, ibid., pp. 18-19. Emilio Orozco Díaz, Lope y Góngora frente a frente, Gredos, Madrid, 1973, pp. 59-66, así como la sátira del cordobés contra Valladolid, de especial significación en este asunto (ibid., pp. 122-123) y la guerra de antologías poéticas Antequera-Medina del Campo. Lope por su parte consideraba a Toledo como su casa (ibid., p. 265). El caso no es sino un dato adicional para la polémica Castilla-Andalucía que tuvo como prólogo la renovadora ruptura poética de Juan de Mena en el siglo Xv y afloró luego con el ataque de Juan de Valdés a Nebrija, el desprecio del condestable don Juan Fernández de Velasco (Prete Jacopín) a Fernando de Herrera, y preludia la obsesión antiGóngora de Lope. Cuenta asimismo la sátira coetánea escrita como entretenimiento espectacular de "ver cómo se arañan y desgreñan las Musas andaluzas con las Castellanas", en Miguel Artigas, "Un opúsculo inédito de Lope de Vega: el 'Anti-Jáuregui’ del Liz. Luis de la Carrera”, BRAE, 12 (1925), p. 594. 
agrandan cada día los tiempos, que no bastan a encubrir los oropeles tempranamente crepusculares de la corona austríaca.

Y aun así queda todavía pendiente la cuestión, tan marcada en la obra, de por qué la villa de Medina del Campo y no otra cualquiera. Que ésta representa allí lo viejo, lo negativo y hasta un poco la necedad pagada de sí misma, es innegable y obvio, pero ¿de dónde esa particularizada inquina hacia ella del otro Lope, es decir el de Vega? Precisa recordar que fue allí donde se originara el conflicto de capa y espada que, de no ser por el Arenal de Sevilla, habría hecho correr un opuesto raudal de lágrimas y sangre y al que, según la historia de Lucinda, vienen ligadas otras razones del orden más privado, que también salen a relucir en el debido momento. Su familia vivía tranquila en la villa (y ella casta enamorada de don Lope a lo largo de seis años) cuando todo saltó por los aires con la presencia accidental de cierto huésped en el seno del hogar paterno. La cercana Valladolid era una ciudad pequeña ${ }^{43}$, pero orgullosa por su tradición de rancia nobleza, capital administrativa bajo la mayor parte del reinado del Emperador y por el prestigio de la Real Audiencia (una de las dos de Castilla) que, ante el meteórico asentamiento de la corte en 1602, hubo de ser reasentada para hacer sitio a Medina del Campo por un Felipe III vuelto en pelele de su valido el duque de Lerma don Francisco Gómez de Sandoval ${ }^{44}$. Y es el craso error y atentado contra el bienestar público de que veladamente se queja Lucinda como origen inmediato o causa segunda de sus desdichas sentimentales:

\author{
Mudó el tercero Filipo \\ su corte, casa y criados
}

43 Bartolomé Bennassar, Valladolid au Siècle d'Or. Une ville de Castille et sa campagne au XVI siècle, Mouton, Paris-La Haye, 1967. Sobre la Chancillería, confirmada en la ciudad desde 1542, y convulsión demográfica que suponía el traslado, ibid., pp. 122-123. No fue ésta la única institución que se vio desahuciada de Valladolid, pues lo mismo ocurrió también con el tribunal del Santo Oficio. Solamente la Universidad, de importancia secundaria, pudo capear el temporal de la impuesta presencia de la corte.

${ }^{44}$ Explicada por María de la Soterraña Martín Postigo, Historia del archivo de la Real Chancillería de Valladolid, Valladolid, 1974. José A. Escudero, "El traslado de la corte a Valladolid", en Administración y estado en la España moderna, Junta de Castilla y León, Valladolid, 2002, pp. 255-273. Las quejas eran patéticas en razón "de la poca salud que allí había, gran descomodidad de aposentos y falta de mantenimientos", como acogía L. CABRERA DE Córdoba en sus Relaciones, p, 227. 
a Valladolid; y fue

mudar también necesario

de allí la Chancillería

con que también se mudaron

mi ventura y muchos pleitos

Quiere decir que, tras el repentino traslado, el hacinamiento de la primera se reproducía aún más agudo en la otra, pues el mismo alto tribunal (cabe añadir) habría pronto de trasladarse (1604) por idéntica razón a Burgos. Se volvía así inevitable la siempre odiosa gabela del alojamiento forzoso en domicilios privados, conforme a la situación inmortalizada por $\mathrm{El}$ alcalde de Zalamea:

\author{
Ennoblecióse la villa, \\ y, como en tiempos pasados, \\ vino a estar con mayor lustre; \\ que, floreciendo sus pagos, \\ poblóse con extranjeros, \\ venidos por varios casos, \\ no habiendo casa sin huésped: \\ causa de todo mi daño; \\ porque le cupo a la mía \\ un noble mancebo hidalgo, \\ de buena presencia y rostro \\ y en la mitad de sus años (II, p. 381).
}

Y de ahí como se recordará la incidencia de Alberto en el domicilio familiar, ocasión del proyecto matrimonial forzado por los padres de Lucinda y el violento desenlace frente a don Lope. Es la historia una seriada desgracia que el espectador de la época podía relacionar en continuidad con la del propio abandonado Madrid, cuyas calles desiertas cubre ahora la hierba y hasta mendigaba que, al menos, se asentara allí como compensación la desahuciada Chancillería ${ }^{45}$. El traslado, desastroso para todos menos para Lerma ${ }^{46}$, que hacía el gran negocio

${ }^{45}$ Lo solicitaba su concejo en septiembre de 1604 como paliativo "para reparar aquel lugar que de día en día se despuebla y sale la gente dél" (L. Cabrera de Córdoba, Relaciones, p. 227)

46 "The removal of the court promoted enormous resentment in Madrid, and was directed to Lerma itself: it was reported that Lerma was cursed in Madrid", escribe PATrick Williams, The great favourite the Duke of Lerma and the court and government of Phillip III of Spain, 1598-1621, Manchester University 
inmobiliario, fue objeto de duros juicios y produjo en Lope, hijo integral del Madrid filipino, una crisis de profunda humillación ${ }^{47}$. Cuando a Valladolid y sus locos placeres ${ }^{48}$ acuden como moscas a la miel todos los poetas de España (Quevedo, Góngora, Cervantes) Lope de Vega es el único que no hace acto por allí de presencia. Con toda intención se marcha a vivir entre Sevilla y Toledo, dos ciudades aparte y con derecho no escrito a ser consideradas como cortes naturales de España, sin precisar para ello de la figura de ningún rey ${ }^{49}$. Y no fue sólo en El arenal de Sevilla donde Lope recogió, intencionado, su querella contra la mudanza de la corte a Valladolid, pues lo hizo también, bajo diversos colores, en La gallarda toledana y en Los amantes sin amor (ambas de 1601-1603), El cuerdo loco (1602) y La prueba de los amigos (1604) ${ }^{50}$. Para Lope la comedia sevilla-

Press, Manchester-New York, 2006, p. 72. Puesta al día del asunto por Alfredo Alvar Esquerra, "La traslación de la corte (1601-1606)", en El duque de Lerma. Corrupción y desmoralización en la España del siglo XVII, La Esfera de los Libros, Madrid, 2010, pp. 169-194.

${ }^{47}$ Lope se hacía ya eco del venidero acontecimiento en 1601-1602. Véase E. Kohler, "La date de «El ejemplo de casadas» de Lope de Vega et la valeur chronologique du "gracioso»", BHi, 47 (1945), 79-91. Fervor madrileñista de Lope en Federico C. SÁinz de Robles, El 'otro' Lope de Vega, Espasa-Calpe, Madrid, 1973, pp. 58-74.

48 Sobre el torbellino de fiestas, galanterías y jolgorios de la corte en Valladolid y su crónica de día a día por el portugués Tomé Pinheiro da Veiga, Germán Vega García-Luengos, "El Valladolid cortesano y teatral de Felipe III", en El duque de Lerma. Poder y literatura en el Siglo de Oro, eds. J.M. Micó et al., CEEH, Madrid, 2011, pp. 355-385.

49 Aparte de al menos una estancia de su niñez, Lope estuvo en Sevilla en 1600, tras dejar el servicio del marqués de Sarriá, con alguna visita también a Toledo, donde tenía su segundo, legítimo hogar, pero parece haber pasado al menos parte de 1602 en Madrid, repartido entre éste y Sevilla, casi de seguro en relación con la entrada en fase activa de sus amores con Micaela de Luján, que le dio un hijo en 1603. Vivió allí con no pequeña actividad literaria todo ese año y al menos hasta el verano de 1604, cuando regesó a Toledo, donde vivía su esposa legítima Juana Guardo, aunque sin abandonar por eso a su amante, que se hallaba en trance de tener otro hijo según los datos de Américo Castro y Hugo A. Rennert, Vida de Lope de Vega, Las Américas, New York, 1968, pp. 140-155. Manuel Cornejo, "«La esclava de su galán» (¿1626?). Nuevos datos acerca de las estancias sevillanas de Lope de Vega", ALV, 9 (2003), 195-210. Valiosas pinceladas del ambiente literario de aquella Sevilla en Antonio Rodríguez Moñino, "Hernando de Soria Galvarro (dos poesías inéditas)”, Mélanges Jean Sarrailh, Institut d'Études Hispaniques, Paris, 1966, t. 2, pp. 281-299.

50 Nadie como Mateo Alemán podía describir el hecho en relación con su Sevilla natal: "Porque, aunque se había hallado bien [su esposa] todo 
na supone a la vez un reproche contra el menosprecio y daño causado a Madrid por conveniencias oscuras de un valido todopoderoso. El capitán Fajardo compara de forma indirecta la escasa prestancia urbana de Valladolid cuando entona su himno a las grandezas de (¡qué mejor corte!) que la ilustre Sevilla:

\author{
...jOh gran Sevilla, \\ que sola tu maravilla \\ de todas tiene el valor! \\ Colosos, anfiteatros, \\ faros, piras, mauseolos, \\ únicos al mundo y solos: \\ estatuas, templos, teatros, \\ no se pueden alabar \\ de que tuvieron grandeza \\ en llegando a la belleza \\ de este famoso lugar (III, 387).
}

Y un poco más adelante, como si no hubiera además otras ciudades de prestigio y altas credenciales, sin ir más lejos en el reino de Aragón, para aspirar al mismo lauro de corte de la Monarquía con que la ilustre Sevilla

\title{
...Compite
}

con las ciudades más graves.

Dejemos la preeminencia, la nobleza y exención en el reino de Aragón, de Zaragoza y Valencia; que esas dos en su corona de España lo pueden ser (III, 387).

Claro que Lope de Vega no dejaba de hacerse violencia en aquel papel de oposición al poder, cuando lo suyo era todo lo contrario y procedía siempre con sumo cálculo, que también en

el tiempo que residió en Madrid y le pareció que hacía la corte ventajas a todo el mundo, con aquella majestad, grandezas de señores, trato gallardo, discreción general y libertad sin segundo, hallaba en Sevilla un olor de ciudad, un otro no sé qué, otras grandezas, aunque no en calidad -por faltar allí reyes, tantos grandes y titulados-, a lo menos en cantidad. Porque había grandísima suma de riquezas y muy en menos estimadas. Pues corría la plata en el trato de la gente, como el cobre en otras partes, y con poca estimación la dispensaban francamente" (Guzmán de Alfarache, ed. J.M. Micó, Cátedra, Madrid, 1994, t. 2, p. 460). 
esta ocasión supo manejar diestramente. El asomo de cualquier censura política carecía en la época de estatuto legal y funcionaba en todo caso como mera antesala de la sátira insidiosa, cuando no de la clandestinidad del pasquín. Menos que nadie, Lope carecía de vocación de mártir, por lo cual huía de complicaciones y lo último que podía desear era el riesgo de cualquier escándalo o paso en falso sobre aquel resbaladizo terreno. En lo que toca a Sevilla busca ponerse a cubierto de la semisoterrada dualidad Castilla-Andalucía, por lo mismo de haberla planteado allí con tanto relieve. Lope prepara bajo cuerda sus coartadas, eludiendo mencionar para nada los nombres de Lerma, de su linaje ni del quejoso Madrid. Atenta no a la protesta, sino a limar previsoras aristas, es la misma sevillana Laura quien se apresura, simultánea, a desautorizar la eventual discordia, pues para eso "todo el cuerpo de Sevilla / es un alma castellana", al tiempo que añade que "también hay blandura acá" (I, p. 372). Lo mismo que, con cautela presente desde el principio, deja caer aquello del Arenal como "otra Sevilla / que está fundada en el río” (I, p. 365). Y dicho además con pleno acierto, pues aquel pedazo de playa asume una vida propia, yuxtapuesta sin transición a la del viejo caserío urbano y no pertenece a nadie más que un futuro que, dado su hallarse in fieri, no posee aún definido estatuto, literatura ni siquiera nombre.

En El arenal de Sevilla su autor el Fénix se hacía un poco al lado cuando arrojaba su piedra contra Medina del Campo, y sólo de modo implícito involucraba su querella contra Valladolid y el traslado de la corte que tanto le dolía. Conocía bien el problema de la privanza que, como en tantas otras ocasiones, madrugó en llevar con frecuencia a las tablas ${ }^{51}$, pero distaba de llegar a homo politicus como, de diversos modos y a pesar de limitaciones, sí ocurría a su alrededor con Cervantes o Queve-

${ }^{51}$ Lope no se hallaba solo. En el tema teatral de la privanza alza conspicuo su cabeza entre 1599 y 1605, con más de una docena de piezas conocidas hasta 1614 y, en mayor o menor grado, relativas a la escandalosa privanza de Lerma. Se repitió un brote similar entre 1621 y 1625, centradas sobre la del conde-duque de Olivares. Lope aborda también el asunto en el auto $L a$ privanza del hombre (1601) y la comedia No le arriendo la ganancia (1614); véase Jesús Gutiérrez, "La privanza en un auto sacramental de Tirso de Molina", Tirso de Molina: vida y obra. Actas del I Simposio Internacional sobre Tirso, eds. J.M. Solá-Solé y L. Vázquez Fernández, Revista Estudios, Madrid, 1987, pp. 87-104. Raíces profundas del tema en RAYMOND R. MaCCurdy, The tragic fall: Don Álvaro de Luna and other favorites in Spanish Golden Age drama, University of North Carolina, Chapel Hill, 1978. 
do. Todo menos tocado de candidez, elude verse atrapado en algo abiertamente comprometedor ${ }^{52}$. El hacerlo a pecho descubierto habría sido una osadía de muy alto riesgo para el poeta, quien lo mismo antes de aquella ocasión que en años venideros, llegaría a extremos adulatorios para captarse el favor de un poder personal cuyos errores y excesos le fueron siempre bien conocidos.

Desde antes de la privanza de Lerma, Lope había sido secretario de don Pedro Fernández de Castro, sobrino del susodicho, marqués de Sarriá, futuro yerno también del privado, y VII conde de Lemos, protector no siempre generoso de Cervantes y discreto poeta él mismo. Fue dicho prócer quien debió facilitar la primera salida tipográfica de Lope, con sus Fiestas de Denia (Valencia, 1599), librito que, en no pequeña dosis, es tributo lisonjero a la confirmada privanza del valido y de su linaje ${ }^{53}$. Siempre en la misma vía, pero sin excesivo éxito y a pesar de algunas reticencias, le anduvo Lope alrededor y hasta acompañó al poderoso ministro en la visita del rey a su feudo burgalés de Lerma a fines de $1615^{54}$. Se veía nuestro poeta en

52 Dicha profunda ambivalencia, fuente de constantes manipulaciones y autocensuras a lo largo de su obra, es sin duda un aspecto fundamental de ésta, que no deja de señalar Alan S. Trueblood: "His circumspection, like the streak of calculation in his histrionics, shows him capable of restraint and self-control when it behooved him to exercise them. It also points to a permanent strain in Lope's nature, namely, an attitude of suvbservience and humbleness of timidity in the face of rank and authority" (Experience and artistic expression in Lope de Vega. The making of "La Dorotea", Harvard University Press, Cambridge, Mass., 1974, p. 46). Matiza la misma actitud BELÉN Atienza, "La [re]conquista de un valido: Lope de Vega, el duque de Lerma y los godos", $A L V, 6$ (2000), 39-50. Para sus reservas acerca de cuestiones de honor, Jesús Gómez, Individuo y sociedad..., pp. 100-107.

${ }^{53}$ Dedicado a doña Catalina de Zúñiga, VI condesa de Lemos, virreina de Nápoles y hermana del valido. Edición moderna a cargo de M.G. Profeti y B.J. García García, Alinea Editrice-Ajuntament de Denia, Firenze, 2004, introducción, "Las fiestas de Denia y el duque de Lerma" (pp. 20-26).

${ }_{54}$ Para el cauto manejo del problema planteado a Lope por la actuación política de Lerma, véanse las insinuaciones a lo largo de su obra que interpreta Melveena McKendrick, Playing the King. Lope de Vega and the limit of conformity, Tamesis, London, 2000, pp. 34, 43, 46 y 52. Acerca de la temprana cronología del mismo, Belén Atienza, "Arte y privanza en «La quinta de Florencia» de Lope de Vega: de los Médicis al duque de Lerma", $B C, 61$ (2009), 1-18. Incluso Fuenteovejuna (1612-14) sería también "una velada censura contra el régimen impuesto por Lerma” para MANUEL FERNÁndez Álvarez, La sociedad española del Renacimiento, Anaya, Salamanca, 1970, p. 139. El provechoso mecenazgo del duque de Sessa inevitablemente 
el incómodo balancín de zigzaguear al pairo entre ambas orillas tanto de la indiferencia como de las larguezas (para él muy tacañas) de aquel dueño de la voluntad real ${ }^{55}$.

De modo similar, también los capitanes Castellanos y Fajardo tratan de amortiguar en su charla el golpe censorio cuando evocan, en término general, el lugar común de cómo "los secretos de los reyes / algo a los del cielo imitan", pues para eso "dueños son de todo. Quitan / ponen y introducen leyes" (III, 387). Un poco filósofos de vía estrecha, pero ajenos a toda veleidad innoble, no son responsables de ninguna acción secundaria, sino esenciales facilitadores o lubricantes del avance lineal de la obra sobre el raíl de capa y espada. El capitán Fajardo ha sido como mínimo cortejante avanzado y no está claro si quizás en titre de Laura, acerca de la cual se juega con una reiterada ambigüedad del verbo "conocer" 56 en etapa anterior al encuentro de ella con el afortunado fugitivo de Medina del Campo. Sólo que ambos hombres de milicia no pisan el Arenal para ocuparse en asuntos privados, sino al servicio de una visión más completa de lo allí en curso. Cuando su valor como puntal del comercio indiano y sus flotas oceánicas es de sobra conocido, Lope desea se conceda justa atención a su otra paralela faceta de base activa en esos años del poder naval de la Monarquía, asimismo ligado al apoyo de una gran ciudad abierta al mar. Sevilla, al ejemplo de Génova, Venecia y Estambul, figura también como señora sobre el mundo en paz o en

tendía a alejar a Lope de la cuerda del valido, según observara JOAQUín DE Entrambasaguas en su ed. de Jerusalén conquistada. Epopeya trágica, CSIC, Madrid, 1954, t. 3, p. 42.

55 Para la actitud hacia Lerma y altibajos en la carrera cortesana de Lope, Marcella Trambaioli, "Las dobles bodas reales de 1615: el triunfo del Lope-personaje sobre el Lope-cortesano”, BHS, 87 (2010), 755-772. Definitiva reafirmación de Lope en su querella contra el alto mundo de la corte, nobleza y mecenazgo regio en JUAN MANUEL RozAs, "El género y significado de la «Égloga a Claudio» de Lope de Vega", Serta philologica F. Lázaro Carreter, Cátedra, Madrid, 1983, t. 2, pp. 465-484. Profundización y puesta al día por Elizabeth R. Wright, Pilgrimage to patronage. Lope de Vega and the court of Philip III, 1598-1621, Rosemont Publishing, Lewisburg, 2001.

56 Así el diálogo en que Alberto sugiere a Fajardo "que Laura os conoce ya", donde la respuesta es "Laura no me conoció; / porque si me conociera, / yo pienso que me estimara" (III, p. 394). Léxico transgresivo de Lope en el conjunto de su obra juvenil que señala Milagros Torres, "Algunos aspectos del erotismo en el primer teatro de Lope", Edad de Oro, 9 (1990), 323-333. 
guerra de la galera mediterránea, pero con la ventaja adicional de serlo a la vez en el de los galeones transoceánicos, que comparten su puerto fluvial. Así como Lope no ha querido penetrar aquí en el mundo del comercio y de la banca hispalenses, lo hace en cambio con regusto en el de la milicia, representado por los flemáticos capitanes, que a su vez son virtuales voceros del propio Lope. Ni idealizados ni traídos por el polvo, dan en su actuación testimonio de un humano praesens historicus que sobriamente habitan como su elemento natural. Sensato y dueño de su materia, el Fénix se ha anticipado a captar con brillantez en su comedia el destino histórico de Sevilla como la hoy reconocida "fortaleza y mercado" 57.

El comienzo de la obra responde a los momentos de mayor esplendor económico de la carrera de Indias ${ }^{58}$ ocupándose como se vio de la partida anual de la flota en la primavera de 1603. Acaba ésta de levar anclas y para cuyo general don Jerónimo de Córdoba y Portugal ${ }^{59}$ traía carta de recomendación el deprimido don Lope. La entrada en escena del personaje dual que integran ambos capitanes no corre sin embargo a su cuenta, sino a la de futuras operaciones norteafricanas que habrán de armarse en aquel mismo escenario. La noticia fresca, traí-

57 Ramón Carande, Sevilla, fortaleza y mercado. Las tierras, las gentes y la administración de la ciudad en el siglo XIV, Universidad, Sevilla, 1978. Publicación original, 1925.

58 Las noticias de L. Cabrera de Córdoba contienen entradas como la del 29 de noviembre de 1603, cuando "hase tenido aviso que han llegado a Sevilla los galeones de la plata de Indias con la flota de Tierra Firme, que dicen traen diez millones y los cuatro para S.M.” (Relaciones, p. 198).

${ }^{59}$ Es el nombre que da Lope (I, p. 366), así como el de su padre don Francisco Duarte, conde de Villar, correctamente identificados por G.I. Dale, quien a la vez no deja de extrañarse de la ausencia de su nombre como general de la flota de 1603. Las dudas se resuelven ahora por los documentos de $\mathrm{P}$. y H. Chaunu que mencionan como capitán general en dicho año de la flota de Tierra Firme a don Jerónimo de Torres y Portugal (Séville et l'Atlantique, t. 4, pp. 104 y 156). Lope sólo cometía, pues, un relativo lapsus (Córdoba por Torres) debido al uso indistinto de ambos gentilicios por el mismo personaje. G.I. Dale consigna también el supuesto error de que no existió flota que partiera de Sevilla en 1603, pues lo hizo en cambio de Cádiz el 29 de junio de dicho año (CABrera, Relaciones, p. 184). Queda confirmada dicha fecha, así como la capitanía general de don Fulgencio de Meneses, pero sólo para la subflota de Nueva España (Séville et l'Atlantique, t. 4, p. 156). La dificultad se justifica por la estrechez portuaria de Sevilla, que obligaba a distribuir el tráfico y los armamentos entre los puertos subsidiarios de Cádiz y Sanlúcar, pero siempre bajo control administrativo de la capital andaluza (Séville et l'Atlantique, t. 8, p. 176). 
da por Castellanos, es el nombramiento como general de las galeras de España de un descendiente de Guzmán el Bueno, don Juan Manuel Pérez de Guzmán, XI conde de Niebla y futuro VIII duque de Medina Sidonia (m. 1636), nombrado el 29 de enero de 1603 general de las galeras de España ${ }^{60}$. Consistía su misión en una enésima jornada contra Argel, redundante de las siempre desdichadas de 1516 (Diego de Vera), Hugo de Moncada (1518) y Carlos V (1541), con la diferencia de que esta vez, en lugar de un ataque directo, se jugaba una carta de auxilio a la insurrección de un contiguo territorio bereber llamado reino de $\mathrm{Cuco}^{61}$. Casi a la vez y con miras a la misma campaña se proveyeron las galeras de Nápoles en el II marqués de Santa Cruz y las de Sicilia en las del hijo del adelantado de Castilla, don Juan de Padilla, conde de Buendía ${ }^{62}$. Una oleada, pues, de altos mandos navales reservados a "caballeros bien mozos" 63 y todos ellos, desde luego, por merced a dedo del duque de Lerma y en especial este conde de Niebla, esposo de su hija doña Juana de Sandoval. Algo sibilinos, si es que no cascados, sue-

60 “A los 29 del pasado, se publicó el cargo de general de las galeras de España que han dado al conde de Niebla, el cual se partirá la semana que viene al Andalucía, para dar orden en las cosas de su cargo" (L. CABrerA DE CórdobA, Relaciones, p. 167). El nombramiento era comidilla pública desde hacía varios días (ibid., p. 166). Las relaciones entre Lerma y Medina Sidonia eran excelentes. El conde de Niebla había sido nombrado cazador mayor y gentilhombre de cámara sin obligación de servicio a fines de 1599, así como en febrero de 1602 sucedía a su padre, el VII duque como capitán general de la costa de Andalucía (ibid., p. 133).

61 Comarca muy fértil, situada en las montañas de la gran Kabilía con salida al mar por el puerto de Azzefun. Su reyezuelo Sidi Amar ben Amar se veía en el trance, común a todo el Magreb, de elegir entre la sumisión al poder turco, afincado a unas leguas en Argel, o al preferible (por distante) del apoyo español. Se dispone de información sobre ofrecimentos de Sidi Amar a partir de 1598 para entregar a Argel si su propio ejército se reforzaba con algún contingente español de desembarco, plan esquemático y de grandes dificultades de ejecución. Véase Carlos Rodríguez Joulia Saint-Cyr, Felipe II y el rey de Cuco, CSIC, Madrid, 1954. Resúmenes de Mercedes García Arenal y Miguel Ángel De Bunes, Los españoles y el norte de África. Siglos XVI y XVII, Mapfre, Madrid, 1992, pp. 131-132; BeAtriz Alonso AcERo, "El reino de Cuco o la volubilidad como táctica de autarquía," en Orán-Mazalquivir, 1589-1639, CSIC, Madrid, 2000, pp. 443-450.

62 Alonso López de Haro, Diccionario genealógico de los reyes y títulos de España, Luis Sánchez, Madrid, 1622, t. 2, pp. 208-209. Su hermana se casó también con otro hijo de Lerma, Cristóbal Sandoval y Rojas, I duque de Uceda.

${ }^{63}$ L. Cabrera de Córdoba, Relaciones, p. 176. 
nan los elogios de su relevo del adelantado de Castilla "como nuevo sol que viene; / que de su puesto sol tiene / de ser el conde sol dado" (I, 371). A la vista del escaso o nulo historial del joven nepote en la marina, ciertamente acarrea y trasluce un si es no es de sorna esta filigrana preconceptista del sol dado, sobre todo puesta al lado del elogio sin reservas de su antecesor en el cargo:

Partióse el Adelantado, y el Conde se adelantó por llegar donde llegó el sol de tan gran soldado (I, 371).

El conde de Niebla se apresura, pues, a colmar el vacío que deja el bravo antecesor ${ }^{64}$, con diligencia que puede leerse como elogio igual que como censura. La misma vaguedad se extiende a la inmediata asociación de astros tan legítimos como el duque de Alba y el marqués de Santa Cruz, don Álvaro de Bazán, en cuya expedición a las Azores había tomado parte Lope en 1582 y de quienes con justicia podía decirse que "La guerra / no ha tenido hombres iguales" (I, 371). Fajardo y Castellanos son valientes y leales, que comienzan por felicitar al padre del flamante general, "Guzmán Bueno entre los buenos" y a "su excelentísima madre" (I, 371), pero también conocen, resignados y de primera mano, la ingratitud de aquel mundo oficial de crasos favoritismos en menosprecio de los viejos soldados ${ }^{65}$. No llegan ni por asomo a la protesta, pero son a la vez presa de la melancolía que arroja un elocuente elemental cotejo entre el antes y el ahora. No se les puede tachar de murmuración, pero

${ }^{64}$ Don Martín de Padilla, adelantado mayor de Castilla por su matrimonio con doña Luisa de Padilla, que en realidad acababa de morir en ejercicio del cargo. Marino al servicio de Felipe II que lo nombró conde de Santa Gadea. Decisivo en asuntos de mar bajo Felipe III y en continua campaña en defensa de las costas occidentales, Canarias y las Terceras, hasta su muerte en el Puerto de Santa María en mayo de 1602. La visible reticencia de Lope se explica por el choque con el duque de Medina Sidonia, quejoso por su furioso ataque, al comienzo de 1602, a unos mercantes franceses y escoceses surtos en la costa de Almería (L. CABrera de Córdoba, Relaciones, p. 153).

${ }^{65}$ La queja no deja de figurar en un rincón del texto. La carta que para Fajardo trae Alberto viene firmada por su colega el capitán Fabricio de León en la dormida Medina del Campo. "Cansóse de pretender", sentencia sin más el capitán Castellanos y confirma el portador: "Cansado ya / de sentir que no merezca / lo que otros muchos que ayer / comenzaron a servir” (III, 388). 
tampoco se aventuran más allá de adornar la noticia con una letra en blanco girada contra futuros heroísmos, que nunca iban a materializarse:

De tal niebla sale el sol

que el África, aunque abrasada, teme el rayo de la espada del nuevo conde español (I, 371).

A la vista, pues del resultado, son palabras vacuamente lisonjeras y que de hecho tiran de las riendas acerca de las hipotéticas dotes del agraciado, igual que había sido el caso de su padre, don Alonso Pérez de Guzmán, VII duque de Medina Sidonia en el forzado mando supremo de la histórica armada de 1588. Tales reservas acusan la perplejidad de Lope, que simpatizaba a las claras con la casa de Guzmán (de siempre muy involucrada en la política local de Sevilla) como permite comprobar El amigo hasta la muerte ${ }^{66}$, comedia cercana en su fecha y de tema también hispalense. Pero, lo mismo que en El arenal de Sevilla y porque todo ha de tener un límite, no deja de traslucir su desazón ante semejante estado de cosas, en que se juega el buen nombre de la Monarquía. Con Lope (se ha comentado también) "conviene pensar mal por principio" 67.

La comedia, en efecto, considera primordial el papel norteafricano de Sevilla como base de operaciones navales. El primer acto busca el modo de hacer sitio para una escena brevísima de leva de anclas, con aparato de salvas, para una jornada de Argel de cierta dificultad histórica, pues no es la del conde de Niebla, del que un momento antes se dice "que venir se apercibe / al puerto" (I. 371), pero no el de Sevilla, sino el Puerto de Santa María $^{68}$, donde solían hallarse surtas las galeras de España. En el segundo acto se describe el Guadalquivir, atestado de galeras para otra jornada contra Argel que, "aunque no es nueva, es

66 Obras de Lope de Vega, Real Academia Española, Madrid, 1929, t. 11, pp. 320-364. Fechada entre 1606-1612 por Griswold Morley y CourTney Bruerton, Cronología de las comedias de Lope de Vega, Gredos, Madrid, 1968, pp. 278-279.

${ }^{67}$ JoAquín de Entrambasaguas, "Las Justas poéticas en honor de san Isidro y su relación con Lope de Vega”, Anales del Instituto de Estudios Madrileños, 4 (1969), p. 71.

68 También, Fajardo, cansado de la vida militar: "Vayan con Dios las galeras; / yo me iré mañana al puerto, / o el lunes, a lo más cierto” (I, 372). Futuros editores deberán de corregir "Puerto." 
honrosa" (II, 378) y el capitán Castellanos declara que se trata de la de don Juan de Cardona, correctamente recordado como héroe de Lepanto ${ }^{69}$, y que partía de Sevilla el 21 de agosto de 1602. Su rumbo inmediato eran Cádiz y Cartagena, donde debía reforzarle un contingente italiano, con lo cual y no sin problemas alcanzó la fuerza, a toda luz insuficiente, de 46 galeras. Una vez en Mallorca, de donde debía partir el ataque, surgió una serie de impedimentos, entre ellos una epidemia, que junto con lo avanzado de la estación y el giro de los asuntos en tierras de Cuco, forzaron una ingloriosa vuelta a Cartagena ${ }^{70}$. Y es lo que, en cabeza del acto tercero, decía el capitán Fajardo, que había participado en aquel remedo de campaña: "No ha tenido efecto nada / de cuanto se imaginó” (III, 387).

Un desastre como el de Carlos V ante Argel, que Fajardo llamaba "historia trágica" (II 378), unida a la eterna pesadilla del corso, pesaba en el recuerdo de todos como una deuda pendiente de saldo ${ }^{71}$. La imaginación era en verdad y por desgracia el manantial de aquellos proyectos, gestados por las mentes calenturientas del reino de Cuco. El reyezuelo moro y los suyos, sabedores de la política de paz exterior adoptada por Lerma, le tentaron siempre con un proyecto que reducía hasta el máximo la intervención militar, concebida como poco más que un simbólico apoyo marítimo a los rebeldes. El plan inicial, elaborado bajo Juan Andrea Doria en 160172, preveía una acción

${ }^{69}$ Lope se hallaba bien informado. Venido de la más alta nobleza de Aragón, don Juan de Cardona mandó como general las galeras de Sicilia bajo Juan Andrea Doria en Lepanto. En 1572 figuró por mandato directo de Felipe II en el consejo consultivo de don Juan de Austria (Luciano Serrano, La Liga de Lepanto entre España, Venecia y la Santa Sede, Junta para Ampliación de Estudios, Madrid, 1918, t. 1, pp. 232, 155 y 366). Frecuente mención de su valor y gran sentido estratégico en La batalla naval del señor don Juan de Austria. Según un manuscrito anónimo contemporáneo, Instituto Histórico de la Marina, Madrid, 1971. Tras su inevitable fracaso volvió don Juan de Cardona a su cargo de virrey de Navarra.

70 Datos de C. Rodríguez Joulia Saint-Cyr, Felipe III y el rey de Cuco, pp. $41-45$.

${ }^{71}$ Con ideas tan desaforadas como la del marqués de Almenara, "Sobre la jornada de Argel que se trató en que avía de assistir el rey Phelipe tercero en las costas de Hespaña (BNM, Ms. 2350)", en la bibliografía de Miguel Ángel DE Bunes IbarRA, La imagen de los musulmanes y del norte de África de los siglos XVI y XVII. Los caracteres de una hostilidad, CSIC, Madrid, 1989, p. 336.

72 Nieto del gran Andrea Doria, brazo derecho de Carlos V en aguas del Mediterráneo. Sobre su desdichada campaña de 1601, C. RodRíGuez Joulia SAint-Cyr, Felipe III y el rey de Cuco, pp. 37-40. 
conjunta de ese orden, que por su propia dinámica pasó después a admitir un desembarco que no pudo realizarse, como sería también la suerte sucesiva de don Juan de Cardona y del propio conde de Niebla. Partía este último de Cartagena el 13 de agosto de 1603 hacia Mallorca con sólo diecisiete galeras, a que después se sumaron algunas italianas, y sólo una fracción de las tropas prometidas. El plan de campaña, aparte de su vaguedad e inmadurez, mostraba una sarta disfuncional que acumulaba retrasos, insuficiencia de la ayuda italiana, escasez de bastimentos, naves en mal estado y para colmo indisciplina y piques sobre protocolo en los mandos ${ }^{73}$. El arrojado virrey de Mallorca, don Fernando Sanoguera, no logró imponer su opinión de arriesgar como fuera un desembarco, que el jefe de la armada consideró inviable dada su escasez de efectivos para una acción frontal contra Argel. Prudente o pusilánime (según se prefiera) la decepcionante jornada quedó reducida a poco más que un paseo o "vista por la mar"74 de su general. El conde estaba de vuelta en Cartagena al cabo de pocos días, cuando se escusaba con el quejoso rey de Cuco por haberse visto atado por el plan a que obedecía y lo inadecuado de su contingente militar por todo lo cual "me resoluí de boluerme"75.

Los datos que preceden proyectan luz sobre el trabajo de Lope en una comedia no deslumbrada, sino profunda y sobriamente conocedora del amplio discurso hispalense, tanto en su realidad fáctica como en su preocupación acerca de la Monarquía desgobernada en manos del valido. Lo indudable es que Lope ha reflexionado sobre el tema del conde de Niebla y del papel de una Sevilla de lleno involucrada para esos años en una política africana de la Monarquía que había entrado en paradójica vía secundaria desde el día siguiente a Lepanto. La comedia de 1603 asume el fracaso no del excelente marino don Juan de Cardona (y de modo tangencial el anterior de Juan Andrea Do-

73 Choques entre Niebla y el duque de Tursi don Carlos Doria, general de las galeras de Sicilia, que se negaba a seguirle alegando hallarse enfermo, "tratándole de Señoría y no de Excelencia, de que se ha quejado al duque de Lerma su suegro" (L. Cabrera de Córdoba, Relaciones, p. 189).

${ }^{74}$ Ibid, p. 189.

75 Carta de 13 de septiembre de 1603 (C. RodríGuez Joulia SAInT-Cyr, Felipe III y el rey de Cuco, p. 129). Aun así no se abandonó el proyecto, continuado en 1604 por la pequeña aventura (tres bergantines) del maestre de campo don Martín López de Eibar, terminada en completo desastre (ibid., pp. 66-70). 
ria) sino de una suprema, arbitraria instancia política al abrigo de toda crítica. No otra cosa pregonaba semejante apoyo, año tras año, de un plan inviable en cuanto a concepto lo mismo que a ejecución, frente a la evidencia de que el ataque a Argel eran palabras mayores militarmente hablando: un error si disculpable en el rey de Cuco, no en el de una gran potencia europea y en que jamás incurriera la prudencia de Felipe II. El capitán Fajardo, haciendo por poner buena cara, afirma que, vista en conjunto, la jornada no ha dejado de ser positiva, siempre una prestigiosa muestra de poder y sana razón de estado, porque lo peor en una guerra es la inacción. Hablaba (no es de olvidar) de la facción de Cardona, pero lo mismo habría podido decir de la del conde de Niebla, todavía en curso para el tiempo de la comedia, pero en todo momento asediada de idénticos errores: "No ha tenido efecto nada / de cuanto se imaginó" (III, 387).

El autor de El arenal de Sevilla no proporciona con seguridad otra cronología que la del nombramiento y primeros pasos de dicha tercera jornada bajo el conde de Niebla, lo cual le fuerza a trabajar con la imaginación él también. Surge por ello el problema acerca de la llegada del conde de Niebla que clausura en guillotina el tercer acto y queda despachada muy por debajo de la despedida de Cardona en el segundo. Es claro que no ocurre a raíz de su designación para el cargo como impide el tiempo interno de la comedia, con los seis meses largos que exige la convalecencia ariostesca de don Lope y más o menos viene a coincidir con un vistoso festejo celebrado por la ciudad hacia el final de agosto de 1603 y del que da concisa cuenta un cronista sevillano: "Domingo 25 del dicho mes [agosto, 1603] alzaron por capitán y sacaron el estandarte del Sr. D. Juan de Austria y fue general de las galeras el conde de Niebla, y fue mucho de ver" 76 . La noticia es en sí extraña y en parte al menos errónea, pues el de Niebla llevaba ya medio año en el cargo, lo ejercía para esa fecha en aguas Baleares y, sobre todo, no se pronuncia a favor ni en contra de la campaña ni de la persona. La escueta gacetilla se limita a lo externo del acontecimiento y nada ilustra acerca de sus motivos. Para mayor frustración nuestra, no podría Lope menos de contemplarlo, si es que se hallaba ese día en la ciudad.

La única certeza en torno al desenlace de El arenal de Sevilla es su modo de hurtar el cuerpo en relación con la alta política

${ }^{76}$ F. DE Ariño, Sucesos de Sevilla, p. 114. 
en torno al conde de Niebla, aspecto en que además no podía Lope mentir para un público hispalense, entre cuya vasta demografía se daban hartas personas capaces de juicio político ${ }^{77}$. En sus versos finales el homónimo personaje don Lope invita a los sevillanos no a celebrar ninguna victoria, sino sólo a "ver" la atronadora salva de arcabuces que el joven conde de Niebla hace a Sevilla, pero no al contrario:

Vamos juntos a la orilla a ver el gran General. dando fin en su Arenal a El Arenal de Sevilla (III, 397).

Son palabras que, con pregón de virtual indiferencia, no corean los capitanes Fajardo y Castellanos. Permanecen mudas las damas, mientras que ambos sus galanes se espantan de aquellos "bravos truenos" y de la "gran tiniebla" o humareda causada por los disparos de unos arcabuces entre bastidores. Sin ningún triunfo que celebrar, la inexistente gloria militar se resume (a lomos de la paranomasia) en la negrura de una nube de humo, sin que el texto quiera darnos alguna luz que aleje de perplejidades en torno a la misma. De lo que no cabe dudar es de cómo Lope de Vega no ha visto en todo aquello nada esperanzador y, menos aún, ningún asidero para un poema en honor del heredero de la casa de Guzmán, sobre la cual parece cernirse el hado fatal del padre ante la herejía en aguas del norte de Europa, repetido en el del hijo ante el Islam en las del Mediterráneo. El premio de ambos fue un piadoso silencio y para ninguno de los dos se alzaron monumentos, ni de las Armas ni de las Letras. El poeta, que escribía durante la huera campaña o aun quién sabe si a raíz de ella, es veterano también de dos acciones navales ${ }^{78}$. La guerra de mar, cercada de inexorables fronteras técnicas, no admite improvisaciones ni descuidos y Lope tiene sus reservas, sus temores y sus nostalgias. Conoce, pues, aquel percal y se niega a ir más allá de la traca que clausura su comedia, sin aclararse acerca del conde

77 J.M. Caballero Bonald, "Patria de claros ingenios", Sevilla en tiempos de Cervantes, pp. 169-173.

78 La de las Terceras en 1582 y la de la llamada (fuera de España) Invencible de 1588, si bien existen fundadas sospechas de su abandono o deserción de esta última al rehacerse las naves de ida de un duro temporal en La Coruña, cuestión que no es aquí de abordar. 
de Niebla pero sí poniéndonos sobre la pista de su frustración con el estro épico, que una y otra vez se le escapa de las manos. A todo trance dispuesto al supremo desafío italianizante de un gran poema de la patria (en el que sólo supo triunfar Camoens) no podía renunciar a su empeño de colmar las medidas de su ingenio. Poseía la ilusión, la capacidad y el empuje, pero no un héroe a que calzar y en La Dragontea (1598) le resultó tal, por antífrasis involuntaria, el inglés Francis Drake ${ }^{79}$. A prueba de inmediatas carencias históricas se conformaría Lope a poco (porque menos da una piedra) con un Alfonso VIII tres cuartos inventado en La Jerusalén conquistada de $1609^{80}$. La gran literatura, sin embargo (y es una gran lección) no siempre vive de días de triunfo. Cervantes, mientras tanto, prefería escribirnos la hermosa derrota final de cierto hidalgo manchego.

Francisco Márouez Villanueva Harvard University

79 Para su origen y fondo histórico, Antonio Carreño, "El canon, Lope de Vega y «El ciclo de juventute»", Morada de la palabra: homenaje a Luce y Mercedes López-Baralt, ed. W. Mejías López, Universidad de Puerto Rico, San Juan, 2002, t. 1, pp. 409-416.

${ }^{80}$ Intenciones, escollos y caprichos de Lope señalados por RAFAEL Lapesa Melgar, "La «Jerusalén» del Tasso y la de Lope", De la Edad Media a nuestros días, Gredos, Madrid, 1967, pp. 264-285. Sobre lo decepcionante de su recepción, Antonio Carreño, "Las trampas de la historia: La «Jerusalén conquistada» de Lope de Vega", Dejar hablar a los textos. Homenaje a Francisco Márquez Villanueva, ed. P.M. Piñero Ramírez, Universidad, Sevilla, 2005, t. 2, pp. 813-835. 